\section{Dollars for biotech}

BIOTECHNOLOGY has received a boost from the University of California (UC) Biotechnology Research and Education Programme. The programme, founded in $\mathbf{1 9 8 5}$ and supported by state funds, has awarded $\$ 1.3$ million in annual grant money to $\mathbf{1 2}$ UC biotechnology research projects at seven of the university's nine campuses.

Major science research grants of $\$ 100,000-\$ 350,000$ were awarded for projects ranging from protein design to development of disease resistance in tomatoes. The programme also awarded smaller grants of up to $\$ 40,000$ for the investigation of issues related to biotechnology, such as a study of options for the commercialization of scientific advances.

M.B.

\section{Optoelectronics push}

THE time is ripe for a major increase in spending on research in optoelectronics in Britain - according to the government's chief advisory committee, the Advisory Council on Science and Technology (ACOST). In a report issued this month, ACOST says that "optoelectronics is vital to our future as an industrial nation" and merits more support, both public and private.

But there is unlikely to be a large injection of public funds, since the government is eager that industry should lead the way with projects determined by market criteria. The report recommends that the government should contribute to a series of demonstration projects of the commercial applications of optoelectronics.

It also recommends that the Science and Engineering Research Council should set up an optoelectronics directorate and give priority to optoelectronics in its scheme for founding Interdisciplinary University Research Centres.

C.McG.

\section{Promising artist}

LEONARDO da Vinci's genius in the fields of science and art is to be the subject of a largescale exhibition in Britain next year. At the heart of the exhibition will be the largest range of Leonardo drawings ever assembled. Also on show will be large-scale models of his architecture from the Museum of Fine Arts in Montreal and the Science Museum in Milan. And specially designed for the exhibition is a flying machine with a wing span of 36 feet, based on Leonardo's drawings.

There will also be computer graphics sequences, made under the direction of Philip Steadman of the Open University, including sequences of Leonardo's architectural projects and a study of the problems of perspective geometry he faced while painting the Last Supper. The exhibition, sponsored by IBM UK Ltd, will be held from 26 January to 16 April 1989 at the Hayward Gallery, London.

C.McG.

\title{
JPL enthusiastic over new slant to parallel computing
}

\section{Berkeley}

THE Jet Propulsion Laboratory (JPL) at Pasadena is hoping that its latest parallel computer, the Mark III Hypercube, will give parallel architecture machines a lead over conventional supercomputers both in speed and in the range of problems for which they can be used.

Although parallel machines have for some time been catching up with the Crays of this world, their advantage has yet to be demonstrated.

The Mark III Hypercube is the third generation of parallel computers developed at JPL, which is owned by the National Aeronautics and Space Administration but operated by the California Institute of Technology. Like its predecessors, the new machine is based on the hypercube architecture, which connects processors as if they were at the corners of a cube in $n$ dimensions.

When completed, the Mark III will have 128 processing nodes, with an architecture based on a 7-dimensional cube, so that each processor will be directly connected to seven others.

With a peak speed of 2,000 million floating point operations per second (2 gigaflops), the Mark III is 10 times more powerful than the NCUBE-10, formerly the most powerful parallel computer, says Carl Kukkonen, director of JPL's Center for Space Microelectronics Technology. Each processor in the Mark III is a Motorola 68020 , with 16 megaflops and about four megabytes of memory.

One objective of the design of the Mark III, said Kukkonen, was to use commercially available parts to keep costs down and at the same time to follow a design that can theoretically be scaled up to create a much more powerful computer. The result, he said, is a performance that already "is equal to and slightly exceeds conventional supercomputers". Comparable in power to the most powerful Cray supercomputer, at $\$ 2$ million the Mark III is one-tenth the price.

Parallel processing computers are often limited to certain types of tasks because software to use them is limited. But Kukkonen says JPL scientists have completed 200 different applications that can be run on the hypercube, demonstrating that it is a broadly usable machine.

The next goal in supercomputers is a teraflop (1 million million flops) machine, and the hypercube can theoretically reach that goal, says Kukkonen. "We can easily imagine going to 10,000 nodes", he says.

JPL is also seeking to develop a machine comparable with the Mark III that is reliable enough to function in space, preprocessing the telemetry from remote sensing satellites. The problem with current parallel computers is that when one node fails, the machine ceases to function. Replacing boards is not a practical matter in space. JPL is therefore developing an ultra-fast switch not only to assist the function of large parallel machines by allowing communication through nodes at 100 times the present rate, but also to allow fault tolerance allowing messages to be routed around bad nodes and substituting spare nodes when necessary.

Marcia Barinaga

\section{Jet simulation}

\section{Washington}

Computational techniques developed by Dr Man Mohan Rai of the NASA/Ames Research Center in California have made possible a three-dimensional numerical simulation, on a Cray-2 supercomputer, of gas flows past the rotating turbines of a jet engine. Rai's computer programme can simulate a pair of turbines, one stationary and one rotating, each of which is a cylindrical drum mounted with airfoil-shaped blades. In the illustration, one set of blades is moving vertically with respect to the other, and the contours show the temperature in the gas flow. The new mathematical technique that allows the fluid-dynamical

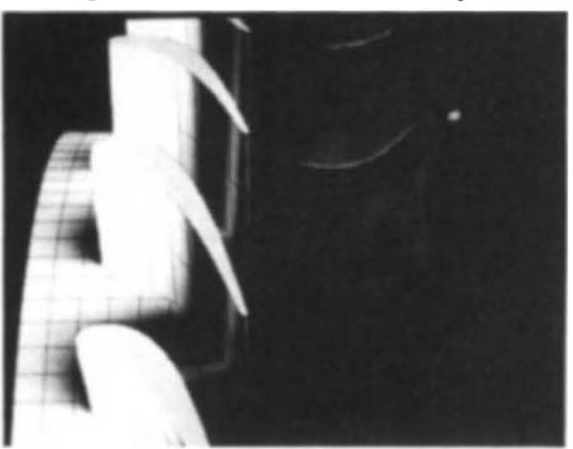

simulation to be done accurately in a reasonable length of time is a method of matching fluid properties (velocity, temperature and pressure) across the boundary between two fine-meshed grids of points, one static, the other moving with the rotating turbine. Even so, the simulation took 100 hours on the Cray-2.

Rai's work has been done with the support of engine builders such as Pratt and Whitney and General Electric, and at a press conference last week NASA officials advertised the research as an example of how federal funds can help US competitiveness. Although Rai's mathematical inventions are to be published, the computer programme itself will be treated as sensitive technology, distributed to US companies but not sent abroad without approval.
David Lindley 